\title{
Development of a Nafion-graphene Nanocomposite for Sensitive Electrochemical Determination of Cadmium(II) Ions
}

\author{
Feng Sun ${ }^{1}$ and Guojing Fan ${ }^{2, *}$ \\ ${ }^{1}$ School of Tourism and Land Resource, Chongqing Technology and Business University, Chongqing \\ 400067, China. \\ ${ }^{2}$ School of History Culture\&Tourism, GanNan Normal University, Ganzhou, Jiangxi 341000, China \\ *E-mail: fanguojing890@163.com
}

doi: $10.20964 / 2017.09 .38$

Received: 5 June 2017 / Accepted: 11 July 2017 / Published: 13 August 2017

\begin{abstract}
In this study, an extremely sensitive electrochemical platform was prepared for $\mathrm{Cd}^{2+}$ detection using a glassy carbon electrode (GCE) decorated with a Nafion-graphene (Nafion-G) nanohybrid. This strategy was based on accumulation of the metal ions on Nafion-G. Raman spectroscopy, XRD, and FTIR were used for the characterization of the prepared Nafion-G. The behaviour of the Nafion-G was optimized using operational parameters and surface modification. In addition, the sensor we developed was successfully used in the detection of $\mathrm{Cd}^{2+}$ in environmental water specimens.
\end{abstract}

Keywords: Graphene; Nafion; Nanocomposite; Cadmium ions; Electrochemical sensor; Water

\section{FULL TEXT}

(C) 2017 The Authors. Published by ESG (www.electrochemsci.org). This article is an open access article distributed under the terms and conditions of the Creative Commons Attribution license (http://creativecommons.org/licenses/by/4.0/). 